\title{
BIBLIOTERAPIA E EDUCAÇÃO: SOPROS DE CUIDADO ENTRE LEITURAS
}

\author{
BIBLIOTHERAPY AND EDUCATION: PUFFS OF CARE WITH READINGS
}

Cristiana Garcez dos Santos Seixas ${ }^{59}$

\begin{abstract}
Resumo
Concebida como arte de cuidar por meio das histórias, a biblioterapia vale-se da leitura como convite a criar espaço para o acolhimento, a expressão, a escuta, a sensibilidade, os vínculos e a construção de sentido. Qual a contribuição dessa prática no contexto escolar? Qual a diferença entre aula de literatura e encontro de biblioterapia? O presente artigo se propõe a responder essas questões, ao mesmo tempo em que busca apresentar a temática: conceito, origens, premissas, propósitos, metodologia e exemplos vivenciados por professoras dentro da escola. São também apresentados resultados de uma pesquisa que teve por objetivo analisar contribuições de espaços-tempos poéticos, simbólicos e expressivos na formação de professores, que incluiu a biblioterapia como um dos recursos metodológicos.
\end{abstract}

Palavras-chave: Biblioterapia. Formação de professores. Linguagens sensíveis.

\begin{abstract}
Conceived as art of caring through stories, the bibliotherapy uses reading as an invitation to create a space for welcoming, expression, listening, sensitivity, bonding and for the construction of meaning. What is the contribution of this practice in the school context? What is the difference between literature class and bibliotherapy meetings? This article proposes to answer these questions and, at the same time, it seeks to present the theme: concept, origins, premises, purposes, methodology and examples experienced by teachers within the school. In addition, it demonstrates the result of a research which not only includes the bibliotherapy as one of the methodological resources, but it also shows the analyzes of the teachers' training's symbolic and expressive poetic space time contributions.
\end{abstract}

Keywords: Bibliotherapy. Teachers' training. Sensitive languages.

59 Psicóloga, biblioterapeuta, especialista em arteterapia, focalizadora de danças circulares, consteladora familiar sistêmica. É mestre em Educação pela UFF, pesquisadora do FIAR (Formação de Professores, Infância e Arte).Email: cristianaseixass@gmail.com .ORCID:0000-0001-7758-8728 


\section{Introdução}

Para o pensamento Guarani, ser e linguagem, alma e palavra são uma coisa só. A palavra ayvu expressa o espírito como som vivo, sopro-luz primeiro, aquilo que é eterno em cada indivíduo e que vivifica o corpo e manifesta-se no reino humano sob a pele da palavra, pelo sopro que a preenche (JECUPÉ, 2001, p. 55).

O sopro da palavra poética foi e é meu instrumento de resistência sensível. $\mathrm{Na}$ memória, encontro pouca ressonância da escola em meu percurso leitor. Pelo caminho, fui habitando a margem e assim, me tornei autodidata. "Livros também podem ser mentores, propiciando até um momento de iniciação." (HILLMAN, 1997, p.178). Fui iniciada a cada leitura, tive muitos mestres. Recebi colo, espelhamento, saídas não imaginadas. Alimentei o sonho e a criatividade. $\mathrm{O}$ apetite leitor foi sendo aberto por tréguas aos combates, em absolvição dos pesos do mundo e criar um momento comunhão por meio da arte. Meus caminhos de formação literária me mostram que o espaço para o encantamento, o imprevisto e o emocionante contribuem para se usufruir das possibilidades ampliadas na imersão do texto literário, como diz Pennac (1993). Processo reflexivo que cria a possibilidade de compreender melhor o homem e o mundo, para nele encontrar uma beleza que enriqueça a existência e que permita ler melhor a si mesmo e ao outro.

O educador poeta Rubem Alves reflete como sendo duas as tarefas da educação: olhar para fora (para as coisas do tempo, efêmeras) e para dentro (para as coisas da alma, eternas). E apresenta as chaves de acesso para as duas dimensões: a ciência e a poesia:

Duas são as tarefas da educação. A primeira delas tem a ver com o primeiro olho: ensinar o mundo que é, a um tempo, nosso corpo e nossa casa. A segunda tem a ver com o segundo olho: despertar a alma para que o mundo não seja apenas um objeto de conhecimento, mas, acima de tudo, um objeto de deleite. Essa capacidade de degustar o mundo é aquilo a que damos o nome de sabedoria. Sabedoria é usar o conhecimento de forma que o mundo se torne um lugar de felicidade. A chave para o primeiro mundo é a linguagem da ciência. A chave para o segundo mundo é a linguagem da poesia. [...] A ciência não nos torna sábios. Daí a necessidade de abrir o segundo olho. $O$ segundo olho leva à alma dos seres humanos onde estão adormecidos os sonhos de beleza e bondade (ALVES, 2003, p. 12-13).

Leituras prazerosas são como respiros, que sopram à alma, despertam e/ou fertilizam sonhos, promovem acolhimento e leveza. Mas, como adverte Pennac (1993, p. 13), 


\section{RevistAleph}

"O verbo ler não suporta imperativo". No caso dos professores, o autor indica que a partilha da felicidade de ler deveria fazer parte do processo de ensino-aprendizagem da leitura. E se o docente não teve oportunidade de ter acesso a repertório que despertasse sua felicidade de ler? Como dar o que não se recebeu?

A escola tem um papel fundamental na iniciação à leitura e ao cultivo de encontros com a literatura, provocando e/ou refinando gostos, ainda que nem sempre cumpra com êxito o determinante papel. A presença ou ausência de incentivo escolar são marcas que carregamos pela vida. Em minha memória, o contato com a literatura na escola está marcado de modo insignificante; certamente outras pessoas terão vivido experiências positivas no espaço escolar. Por exemplo, Maria Bethânia, grande artista brasileira, agradece a seu professor ginasial, Nestor de Oliveira, pelos devaneios poéticos proporcionados durante as aulas de português:

Em suas aulas, além de didática, aprendia-se a ouvir, ler e dizer poesia. [...] Isso acontecia numa escola pública do Recôncavo baiano. [...] Eu fui aluna de escola pública, eu Maricotinha, e recebi a comenda "Ordem do Desassossego" em reconhecimento pela divulgação da obra de Fernando Pessoa. Obrigada, professor Nestor! Bravo! (BETHÂNIA, 2015, p. 97).

Teria sido a experiência de "ouvir, ler e dizer poesia" com seu professor na escola pública, a semente para fecundar todo seu percurso profissional que encanta a tantos? Olhares poéticos são arados e semeados também na escola, quando a arte, no caso a literatura, é vivida compaixão, envolvimento e sentido.

Na Grécia antiga, por meio dos poemas homéricos da llíada e da Odisséia, revelavase o caminho para transformar-se num ser essencialmente humano, virtuoso. A poesia era o acesso estético à dimensão ética. A arte era reconhecida como veículo de conversão espiritual, com privilegiado poder humanizador (OUAKIN, 1966). Num mundo dominado pela ciência e a tecnologia, a literatura hoje é vista como uma espécie de verniz cultural, de importância relativa e complementar, diferentemente de um passado não muito distante, quando a literatura era elemento central da formação dos indivíduos e na estruturação da cultura da sociedade (GALLIAN, 2017). A literatura é uma manifestação universal, presente em todas as culturas, pela necessidade humana de fabulação e fantasia (CANDIDO, 2011). A leitura não impõe, propõe. Assim, convida à reflexão sobre discursos dominantes e tem vocação para proporcionar debate de ideias. Convida também a habitar outros espaços, 


\section{RevistAleph}

permitindo ao mesmo tempo escapar e encontrar, a formar moradias provisórias, a restaurar a esperança. "Ler tem a ver com a liberdade de ir e vir, com a possibilidade de entrar à vontade em um outro mundo e dele sair. Por meio dessas idas e vindas, o leitor traça sua autonomia, mediante a qual ele se reconstrói." (PETIT, 2009, p. 92).

A antropóloga Michele Petit realizou pesquisa junto a mediadores de leitura espalhados pelo mundo, em locais marcados por dificuldades: assolados por guerras, pobreza, campos de refugiados etc. A autora escreve sobre a "doença do olhar", em que a pobreza extrema, a angústia e maus-tratos, matam o olhar e impedem de se imaginar melhor alternativa. Pessoas traumatizadas reavivam permanentemente as mesmas cenas. Nesse sentido, rodas de leitura são espaços para partilhar e nomear angústias, fomentar apoios, criar imagens e renovar esperanças. A leitura é uma forma de acessar boa quantidade de personagens, que contribuem para diminuir a sensação de desamparo para enfrentar o desconhecido. A autora pergunta: "O salto da literatura oral ou escrita, pode contribuir para curar o olhar?" (PETIT, 2009, p. 101). Em minha experiência como mediadora de rodas de leitura semanais, desde 2011, percebo que a leitura partilhada resgata nossa oralidade, nos reconecta com a prática ancestral de intercambiar experiências e tecer vínculos. Assim, desarmados, disponibilizamo-nos ao olhar outro, como janelas a espreitar outras lógicas, crenças e possibilidades.

A leitura põe o pensamento em movimento, ativa a simbolização, a construção de sentido e narração. Se algo dolorido é dividido com o autor, com aquele que lhe empresta a palavra e a voz, abre-se espaço para a intimidade, para afetividade, para a sensibilidade. São em páginas dolorosas que nossas histórias podem ser lidas de maneira indireta: “[...] dentro das letras estão vozes. Cada página é uma caixa infinita de vozes. Ao lermos não somos o olho; somos o ouvido." (COUTO, 2015, p. 229). Mas, ao evocar essas vozes por intermédio da leitura, é necessário criar espaço para escuta, onde o afeto esteja presente para permitir o acolhimento dessas narrativas. Nesse sentido, percebo que os conceitos e premissas da Biblioterapia, que venho pesquisando e praticando, poderiam contribuir para tecer espaços de acolhimento, escuta de vozes e sopros literários no contexto escolar e na formação docente. Mas o que é biblioterapia? Qual a diferença entre uma aula de literatura e um encontro de biblioterapia? De que formas poderia ser aplicada ao contexto escolar? A proposta deste artigo é discutir essas questões. 
Biblioterapia: conceitos, origens e propósitos

Biblioterapia é a terapia por meio de livros (OUAKNIN, 1996). A palavra deriva do grego, composta dos termos Biblion e Therapein. Biblion diz respeito à material bibliográfico e de leitura, já Therapein significa tratamento, cura ou restabelecimento. O livro, porém, é apenas o dispositivo que armazena as palavras, histórias e ideias, que poderia ser substituído por plataforma digital (como Kindle, Ipad, laptop, celular, por exemplo), ou até mesmo pela oralidade (SOUSA, 2017). Em certas culturas, como a africana, os mais velhos são considerados bibliotecas vivas, por serem guardiões das histórias (TELLES, 1980). Terapia é a arte de cuidar. É atitude de ocupação, preocupação, responsabilização e envolvimento afetivo com o outro (BOFF, 1999). Nessa perspectiva, biblioterapia é a arte de cuidar por meio das histórias, sejam elas escritas, faladas ou dramatizadas (CALDIN, 2010). É importante ressaltar que não se trata de qualquer história, de qualquer livro. A questão fundamental é selecionar o livro, a história, o texto que dialogue com o contexto e o público envolvido. Biblioterapia é a utilização da palavra a serviço do cuidado. Kaká Werá Jecupé (2001), em Tupã Tenondé, nos revela, por meio da sabedoria ancestral Guarani, que a palavra é a pele do sopro. Dessa forma, o sopro da palavra é o veículo de cuidado do ser, a matéria prima da Biblioterapia.

Nas origens históricas da prática, no século I, no Egito, por meio do livro "De vita contemplativa", Fílon de Alexandria descreve os filósofos como médicos, por cuidarem das doenças do psiquismo. É a partir desse reconhecimento do que anima o corpo, o sopro de vida, que o cuidado espreita outras formas de terapia: “Curar alguém é fazê-lo respirar, dar espaço ao sopro [...] o desabrochar da alma em um corpo. O papel do terapeuta será o de desatar esses nós da alma." (OUAKNIN, 1996, p.14). A poesia, recheada de enigmas, abre para plurais caminhos, e assim, nos ajuda a respirar bem: "A poesia é uma alegria do sopro, a evidente felicidade de respirar" (BACHELARD, 2001, p. 245). O poeta Mario Quintana (1999, p. 155) escreve sobre "a inquieta voz de vento que me chama". A palavra hebraica nashak quer dizer "compartilhar o sopro" e, por extensão, "beijar". Soprar a palavra certa é como beijar a alma de quem a escuta. A biblioterapia tem compromisso com o sopro sensível.

Por compreender que a literatura é linguagem, lugar de passagem, morada de palavras e silêncios, constato que, utilizada a serviço do cuidado, pode auxiliar na construção 


\section{RevistAleph}

de espaço para respirar, divagar, tecer vínculos e, quem sabe, encontrar sentidos. Nesse sentido, a liberdade na escolha do acervo e na forma de ler são essenciais. Yolanda Reyes (2012) educadora colombiana, defende a criação de espaço para leituras transgressoras. Em suas palavras: "Algumas vezes temos de ser obedientes ou literais, outras necessitamos analisar com exatidão textos científicos e acadêmicos, da mesma forma precisamos de ferramentas para fazer leituras livres e transgressoras." (REYES, 2012, p. 26). Ela testemunha, junto à dura realidade na Colômbia, questões globais contemporâneas, em que crianças e jovens estão imersos em cultura de pressa e tumulto que não permite refúgio no profundo de si mesmos. A educadora defende que a experiência do encontro com livros reveladores, lidos não com os olhos ou a razão, mas como o coração e o desejo, são essenciais para que casas interiores sejam construídas. E ressalta a importância das conversas de vida tecidas entre as linhas: "No fundo, os livros são isto: conversas sobre a vida. E é urgente, sobretudo, aprender a conversar." (REYES, 2012, p 29).

Com Yolanda Reyes (2012) compreendemos que conversar sobre a vida é uma premissa importante para o ensino da leitura e para aprofundar o contato com os livros. Para conversar, é preciso escutar; e este é um ponto decisivo na Biblioterapia: a escuta é fundamental. Escuta no sentido de ser sensível ao outro, de criar espaço para estar disponível a ele. Paulo Freire lembra que ensinar exige saber escutar: "Se na verdade, o sonho que nos anima é democrático e solidário, não é falando aos outros [...] que aprendemos a escutar, mas é escutando que aprendemos a falar com eles." (FREIRE, 1996, p. 113). No método da Biblioterapia, após a escuta, suspeita-se de algum livro que possa contribuir: "Cada escuta acorda uma suspeita" (QUEIRÓS, 2007, p. 13). Oferecido o livro, feita a leitura, a resposta ao texto ofertado é de extrema relevância no processo, é o próprio propósito do trabalho: evocar as narrativas dos participantes. Em meu ofício observo o quanto a falta de espaço e de repertório de palavras de conteúdos represados gera agressividade e sintomas. A antropóloga Michele Petit observou o mesmo:

Quanto mais formos capazes de nomear o que vivemos, mais aptos estaremos para vive-lo e transformá-lo. Enquanto o oposto, a dificuldade de simbolizar, pode vir acompanhada de uma agressividade incontrolada. Quando se é privado de palavras para pensar sobre si mesmo, para expressar sua angústia, sua raiva, suas esperanças, só resta o corpo para falar: seja o corpo que grita com todos os seus sintomas, seja o enfrentamento violento de um corpo com outro, a passagem para o ato (PETIT, 2009, p. 71). 


\section{RevistAleph}

Grada Kilomba, psicóloga, psicanalista e artista interdisciplinar pesquisou sobre os processos sofisticados de colonização que são perpetuados por desconhecimento. Ela afirma que: “[...] o ato de falar é uma espécie de negociação entre quem fala e quem escuta. Ouvir então seria ato de autorização em direção ao falante. Ou seja, alguém só pode falar somente quando sua voz é ouvida. Nesse sentido, os que são ouvidos são também aqueles que pertencem." (KILOMBA, 2019). A simples criação de um espaço de escuta desarma agressividades. Yolanda Reyes expõe o cenário de recrutamento de jovens pelo tráfico de drogas na Colômbia: "cerca de onze a catorze mil menores de idade recrutados por grupos armados ilegais. [...] Os testemunhos falam como as armas e os uniformes lhes dão um sentido de pertencimento." (REYES, 2012, p. 65). São jovens que vivenciam em seu lar e seu bairro maus-tratos, abuso sexual, miséria e abandono. O grupo armado então se transforma em opção de vida. Que alternativas vislumbram a essa cultura delinquente, com narrativa única? Conforme aponta a autora, a escuta e a oferta da literatura poderiam contribuir para inventar formas outras de pertencimento, novos horizontes e acolhimento à dor gerada por certas realidades:

\footnotetext{
A literatura pode ajudar essas crianças e esses jovens a escutarem sua própria voz, em meio ao concerto de vozes, nos interstícios das páginas, e auxiliá-los a esquadrinhar, na polifonia de relatos, daqui, de lá, de longe e de perto, algum resquício onde seja possível agregar uma palavra nova, um novo sentido, uma emoção, um dado inadvertido. A necessidade de lamber a ferida com as palavras (REYES, 2012, p. 81).
}

Nessa urdidura simbólica, a literatura pode assumir o papel de caixa de ferramentas na necessária tarefa de atiçar as próprias vozes, de saber inventar para se conhecer, juntar os pedaços, construir um mosaico que acolha a fragilidade e a beleza na comunhão de nossos cacos. 


\section{RevistAleph}

\section{A diferença entre aula de literatura, contação de histórias e biblioterapia}

A discussão aqui proposta não pretende diminuir a importância do ensino de literatura na escola, da sua contribuição para a formação do leitor e de aulas e/ou metodologias que garantam o acesso democrático a repertórios literários múltiplos. 0 objetivo é indicar a emergência de um campo de conhecimento cuja premissa fundante é que, na perspectiva da biblioterapia, o propósito maior é abrir espaço para a pessoa, o grupo, o contexto e suas narrativas (em palavras, imagens ou silêncios). A seleção do livro ou da história é etapa fundamental do processo, que parte da escuta, entendida como leitura do outro e da situação. Antes do "o quê", vem o "para quem" e o "como". Se na aula, geralmente, há um programa a ser cumprido, muitas vezes sem possibilidade de flexibilização da ementa curricular (que é um desafio para educadores, impelidos a dar conta de grandes conteúdos na pequena duração de uma aula), na biblioterapia, o compromisso é fomentar diálogos, reflexões e releituras, a partir de questões suscitadas pelo grupo. É experiência estético-reflexiva (GALLIAN, 2017). O espaço para as reverberações e fala dos participantes é criado e considerado propósito maior do encontro. Um trecho do livro "Os três reis", do educador Rubem Alves, traduz essas diferenças metodológicas:

\section{COMO LER UMA HISTÓRIA}

Ao terminar a leitura de uma estória ou de um poema jamais pergunte: “ $O$ que é que o autor queria dizer?" Porque, ao fazer essa pergunta, você estará afirmando que o autor queria dizer uma outra coisa diferente daquela que ele disse. E, com isso, você o estará acusando de incompetência linguística. Um autor jamais quer dizer uma outra coisa. Se ele escreveu o que escreveu é porque ele queria dizer o que escreveu. Se tivesse querido dizer uma outra coisa, ele teria escrito essa outra coisa, e não aquilo que escreveu. Assim, não tente interpretar o texto. Entregue-se, simplesmente, ao seu gozo. Mas você poderá fazer outras perguntas: "O que é que esse texto me fez pensar? Por que caminhos da imaginação me fez voar?" A resposta a um texto não é interpretação. É o outro texto que você, leitor, produz inconscientemente enquanto lê... (ALVES, 2004, n.p.).

A liberdade de ler de forma insubordinada traz leveza e permissão, é respiro. O que já tira o fardo da colonização das ideias. No formato da biblioterapia, não há provas, avaliações nem exigências. O desafio é abrir passagem para o fluxo: "Como fazer o homem sair de um 'estado de aprisionamento' e permitir que encontre um espaço de eclosão e de 


\section{RevistAleph}

desabrochar para uma livre circulação do impulso vital, que faz dele um sopro falante vivo?" (OUAKNIN, 1996, p. 126). E, para criar esse espaço, o erro e o inacabamento são bem-vindos. Costumo recorrer a trechos da literatura para criar atmosfera de permissão ao erro, como por exemplo: "A maior riqueza do homem é a sua incompletude. Nesse ponto sou abastado. [...] Perdoai. /Mas eu preciso ser Outros." (BARROS, 2010, p. 374); Fernando Pessoa, em seu célebre Poema em linha reta: "Arre, estou farto de semideuses. /Onde é que há gente no mundo?" (PESSOA, 1996, p. 86) ou Eliane Brum (2014, p. 142), a jornalista que encontrou forma de lidar com a timidez: "Aos poucos percebi que só poderia me colocar diante do outro, de todos os outros, como eu era. Quebrada. Com toda a integridade das minhas fraturas, das quais finalmente fiz um vitral. Uma quebrada diante de quebrados, esse é o pacto em meus encontros públicos".

Colocar a voz na roda é um ato político, que requer exercício de liberdade, fortalecimento da autoestima e acolhimento da diversidade. Outra premissa da abordagem é o respeito às diferentes opiniões. Se alguém tem uma visão totalmente diferente do outro, não há discussão para chegar a uma conclusão. Partimos da premissa que não há o certo e o errado. Cada um tem o direito de expor suas argumentações e o dever de silenciar para que o outro também tenha essa chance. Se alguém desejar mudar de visão ou opinião posteriormente, trata-se de escolha pessoal.

E, nesse espaço onde há a coragem de partilhar as fragilidades, humanizamo-nos em comunhão, formando o que o filósofo Jacques Ranciére (2009) chamou de "fábrica do sensível", pela constituição de mundo sensível comum, habitação formada pelo entrelaçamento de partilhas.

Uma diferença marcante é no papel do professor, do contador de histórias e do mediador. Na aula de literatura ou na contação de histórias, geralmente os professores ou os contadores, conforme o caso, é que trazem e/ou apresentam determinada obra literária (ainda que a escolha do livro seja definida pelo currículo ou por necessidades de variadas origens). Na proposta da biblioterapia, o principal papel a ser desempenhado pelo mediador/responsável pela atividade é o de ouvinte. Sua arte primeira será ouvir o grupo para posteriormente escolher livros que dialoguem com as questões suspeitadas. Depois, durante o encontro, oferecerá a história, o livro, para que seja lido pelos participantes (em exercício de oralidade, de manejo com o instrumento da palavra), com direito a repetir a 


\section{RevistAleph}

leitura, a experimentar entonação diferente, a se apropriar da língua, do vocabulário. É fundamental que o mediador de biblioterapia fique atento às linguagens outras, talvez vindas de sinais corporais, como engasgos, choros, lábios cerrados, olhares. Essa postura requer inteireza ao momento presente, antenas de poeta para os fenômenos e linguagens além das palavras. Ficará também na responsabilidade de promover equilíbrio nas participações, seja incentivando os mais calados ou buscando conter aqueles que desejam tomar o tempo do grupo para si. Trabalha assim os elementos feminino e masculino: um que acolhe e cuida; outro que estabelece limites. $\mathrm{Na}$ aula de literatura, há um roteiro a ser seguido. $\mathrm{Na}$ biblioterapia, há uma trilha: “Quem anda no trilho é trem de ferro. Sou água que corre entre as pedras: liberdade caça jeito" (BARROS, 2013, p. 28). A formação recomendada é em roda, símbolo universal, que tem a vocação de equilibrar as forças da diversidade, com oportunidades iguais e acolhimento.

\section{Experiências da biblioterapia na escola}

Paulo Freire escreve sobre o verso de Camões: "C'um saber de experiências feito" para reforçar o valor de saberes adquiridos na prática, seguidos de reflexão crítica e contínuo aperfeiçoamento e aprofundamento (FREIRE, 1995). Foi inspirada em Freire que ousei iniciar no campo da Biblioterapia, para aprender com ele. Essa história iniciou em 2011, com círculos de biblioterapia semanais, que alavancaram muitos movimentos posteriores. Tenho oferecido cursos livres sobre o assunto desde 2015, que são procurados por pessoas oriundas de áreas variadas, inclusive por educadores que buscam instrumentos e abordagens para humanizar métodos de ensino. Após o curso, alguns participantes iniciaram suas próprias vivências dentro de escolas, com resultados surpreendentes.

Fabíola Barcelos, professora do CIEP Maringá na cidade de Macaé-RJ, participou do primeiro curso livre de Biblioterapia, em outubro de 2015. Era grande seu interesse em aplicar os preceitos e metodologia da prática na escola em que trabalhava. Leitora voraz, já tinha farto repertório que transbordava em seu perfil "Passarinhos no sótão" nas redes sociais. Porém, diante da possibilidade de utilizar a literatura para cuidar, temia não ter estrutura de dar conta de abordar os terrenos da psique, sem ser psicóloga. Esse receio é partilhado por muitas pessoas. Clarice Caldin, referência na temática no Brasil, divide a biblioterapia em dois 


\section{RevistAleph}

tipos: de desenvolvimento e clínica. A clínica seria de responsabilidade de psicólogos e a de desenvolvimento poderia ser trabalhada por bibliotecários (CALDIN, 2010). Na Polônia a história é diferente. A partir de 1980, a Biblioterapia começou a ser oferecida nas universidades como pós-graduação, além de treinamentos na área serem oferecidos em outras instituições como bibliotecas, escolas de artes e associações (SOUSA, 2017). Naquele país, a prática é reconhecida como interdisciplinar e praticada por várias áreas, diferentemente do Brasil, que, de acordo com o Código Brasileiro de Ocupações, consta como atividade inerente à biblioteconomia (SEIXAS, 2018b). Ainda há muito a evoluir no reconhecimento e disseminação em outras áreas. Reconheço as preocupações, porém essas barreiras não são tão nítidas assim. Quem me inspirou a incentivar profissionais de outras áreas a trabalhar com a biblioterapia foi Nise da Silveira (1905-1999), psiquiatra que revolucionou o tratamento da loucura. Ela buscava pessoas sensíveis tanto para lidar com os doentes mentais, quanto para participar do grupo de estudos, independentemente da formação ou títulos conquistados. Ela interessava-se por pessoas capazes de perscrutar o olhar do outro, sem medo do inconsciente (MELLO, 2015). Acredito que esse também seja o pré-requisito para trabalhar com a biblioterapia. Observo que pessoas apaixonadas por livros, quando os compartilham com pessoas, a arte de cuidar já se faz presente, independentemente da formação ou da intenção. A psique busca continuamente por espaço e expressão. Se esses não são ofertados, fala por outros meios, como revela Eduardo Galeano (2000, p. 23):

\footnotetext{
Quando é verdadeira, quando nasce da necessidade de dizer, a voz humana não encontra quem a detenha. Se lhe negam a boca, ela fala pelas mãos, ou pelos olhos, ou pelos poros, ou por onde for. Porque todos, todos, temos algo a dizer aos outros, alguma coisa, alguma palavra que merece ser celebrada ou perdoada.
}

Venho, ao longo das andanças, observando exemplos inspiradores, como por exemplo o poeta Sérgio Vaz. Ele não é psicólogo, mas faz um trabalho incrível que promove acolhimento, expressão, nutrição afetiva, empoderamento e sentimento de pertencimento na periferia de São Paulo e outras localidades, através do Sarau da Cooperifa, que existe há mais de 15 anos em Taboão da Serra, São Paulo. Estive no local e fui testemunha da nutrição poética e estética e do convite a transformar as travessias da vida em palavras: moradores de rua, travestis, estudantes, idosos, jovens, todos partilhando espaço de luta e ternura através 


\title{
RevistAleph
}

da poesia. Nos versos e atos de Vaz, a palavra se faz abrigo, ponte e inclusive arma, diante da violência circundante:

\author{
Sou poeta \\ e como poeta posso ser engenheiro \\ e como engenheiro \\ posso construir pontes com versos \\ para que pessoas possam passar sobre rios \\ ou apenas servir de abrigo aos indigentes.
}

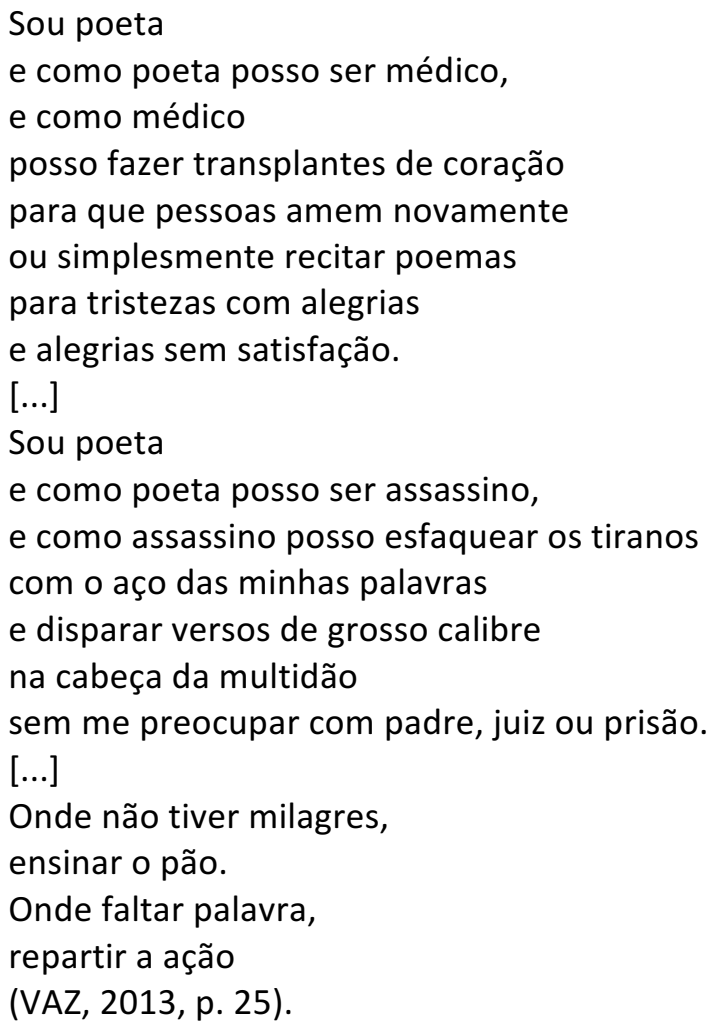

Esse muro entre o que é do campo da psicologia, educação, saúde, cultura é tênue. Fronteiras são criadas pela nossa limitação face à complexidade humana. Qualquer um que trabalhe com pessoas e livros sabe que eles afetam as emoções e, em muitas ocasiões, a pessoa transborda. Não há como prever a reação das pessoas diante das rodas. Qual é o maior temor? De alguém descompensar, chorar? É sinal de expressão, de fluxo das emoções, o que, por si só, já é terapêutico. Não necessariamente é preciso dar uma resposta. A confiança é conquistada a partir das situações atravessadas no campo da experimentação. Nesses casos, utilizo a própria literatura para dar permissão à expressão das emoções, como por exemplo: "Lágrima é feita de água e sal. Isso mostra que existe um mar morando dentro da gente. Chorar é deixar o mar transbordar. Chorar é não querer morrer afogado." (QUEIRÓS, 2018, p. 


\section{RevistAleph}

24-25). Mia Couto revela o pranto como voz e evidência de humanidade: “O pranto é o consumar de duas viagens: da lágrima para a luz e do homem para uma maior humanidade. Afinal, a pessoa não vem à luz logo em pranto? O choro não é nossa primeira voz?" (COUTO, 2009, p. 100); Se o choro transborda, é indicativo de uma ferida aberta, alguma questão que precisa de atenção: "Minhas tristezas estão maduras. Só tristezas verdes precisam de água para crescer." (QUEIRÓS, 2004, p. 16). Ao permitir o fluxo das águas internas, nova visão é alcançada, como revela a poeta amazonense: "Lavei os olhos com muitas lágrimas, agora vejo melhor." (CABRAL, 2004, não paginado). Para encerrar os exemplos, eis a preferida definição: “Lágrima é a água que o amor derrama quando precisa ser visto." (BORGES, 2018, p. 29). Outra prática que incentivo é ter contatos de profissionais psicólogos ou serviços de psicologia aplicada para encaminhamento, quando necessário.

Retornando ao caso da Fabíola, após o curso, foram trocadas inúmeras mensagens, para tirar dúvidas e incentivar a coragem de começar. Ela chegou a fazer o curso pela segunda vez, em 2017. Levou tempo necessário de maturação para iniciar suas experiências, dentro e fora da sala de aula. Na escola, criou o projeto "Ninho de Leitores", de promoção de atividades como: mediação de leitura, oficinas literárias, empréstimo de livros e rodas de biblioterapia. A escolha do nome "ninho" foi apropriada, pois, na perspectiva de Bachelard (2008, p. 106) "o ninho é o esconderijo da vida alada". Equivale à criação de espaço como refúgio, de recolhimento a um canto, que desencadeia devaneio de esperança. Foram realizados círculos de biblioterapia junto a alunos (inclusive em correção de fluxo), professores e responsáveis pelos alunos. Criou-se assim, espaço para o diálogo, fomentado pela literatura. Nas rodas, foram utilizados livros infantojuvenis aplicáveis para todas as idades, como por exemplo: "Ernesto" (FRANCO, 2016); "A garrafa e a rolha" (AMARAL, 2015), “A força da palmeira” (LOPES, 2014), "O menino Nito" (ROSA, 2008). Um desses especificamente criou profundas reverberações: o "Ernesto". Na história, todos dizem algo sobre o protagonista e ele vive muito sozinho e a história aparentemente acaba assim. Após a perplexidade do fim, a narrativa continua mostrando que tem gente que nem percebe que a tristeza não está só no final, mas na história inteira do Ernesto. Fabíola materializou o personagem num boneco, que circulou entre os alunos, para que pudessem expressar o que a história despertou em cada um. Numa outra atividade, foi feita a leitura de "NÓS" (FURNARI, 2003). Na história, a protagonista, de tanto segurar choro e mágoa, acabou formando "nós" em seu corpo, que 


\section{RevistAleph}

foram ficando cada dia mais difíceis de esconder (apareceu nó até no nariz). Decidiu então partir de sua cidade, onde descobriu, com novos amigos, uma maneira de desfazer os nós: contando histórias sobre cada um deles. A professora então distribuiu a cada aluno um pedaço de barbante para dar nós e escrever sobre suas histórias. São exemplos inspiradores para tratar de questões delicadas através da literatura, oportunizando pausa nos desafios diários, com chance para o cuidado de si, em atividade que, simultaneamente, promove fomento cultural. Para os alunos, representou a possibilidade de se reconhecerem e compreenderem o outro através das histórias, com reflexões sobre a vida e as relações. Os participantes começaram a relatar e a mostrar mudanças de postura no cotidiano.

Uma outra professora e psicopedagoga de Nova Iguaçu - RJ, também participante do curso de Biblioterapia, ficou impactada com o potencial da literatura infantojuvenil em tocar em assuntos densos, de forma lúdica. Decidiu adotar livros apresentados durante o curso, como o "Ernesto", como estímulo para Oficina de Letramento: parte do projeto desenvolvido em conjunto com outras profissionais (das áreas da psicopedagogia, fonoaudiologia e psicomotricidade), direcionado a crianças e adolescentes, de 06 a 14 anos, com transtorno de aprendizagem. O propósito do projeto do Núcleo Especial de Apoio Pedagógico é modificar a relação da criança com o aprendizado, no sentido de despertar o interesse e o prazer na leitura, provocar identificações, fortalecimentos e transformações, aliando cognição com afeto. São crianças marcadas por exclusões, com baixa autoestima pelos preconceitos sofridos pela incapacidade de acompanhar o padrão (por inquietação, idade avançada, transtornos etc.). É o poeta Manoel de Barros que nos devolve a humanidade, diante das engrenagens do sistema: "As coisas jogadas fora têm grande importância, como um homem jogado fora. [...] As coisas jogadas fora são bens de poesia." (BARROS, 2010, p. 147). Esse projeto foi contemplado pelo Prêmio Paulo Freire na Educação Pública, entregue dia 14 de novembro de 2019 na UFRJ. Liane Félix partilhou comigo sua alegria e encontrou um manancial de possibilidades por meio da biblioterapia.

Cristina Lúcia atua no Instituto de Educação Professor Ismael Coutinho (IEPIC), em Niterói-RJ. Após o curso, iniciou suas experiências em 2019 com rodas no formato da biblioterapia (disposição em roda, com mandala de livros selecionados ao centro) junto a alunos do 70. ao 9․ ano do ensino fundamental e do 1ㅇ. ao 3‥ ano do curso normal. Ela relata da experiência dos alunos lendo Cecília Meireles, de uma que lia chorando e, diante da oferta 


\section{RevistAleph}

de outro aluno para continuar, ela se negou fazendo questão de ir até o final, como uma travessia, uma catarse. Outro aluno teceu ponte dos poemas com seus próprios e teve oportunidade de apresentá-los na turma. A partir dessas experiências, Cristina passou a ter um outro olhar para a literatura. Paralelamente, assim como Fabíola, passou a oferecer rodas fora da escola, em exercício contínuo de cuidar de si e do outro simultaneamente, criando campos saudáveis por meio da literatura.

\section{Biblioterapia na pesquisa: o Estúdio do Sensível}

Depois de anos trabalhando com a biblioterapia, individual e coletivamente, sendo testemunha de tantas histórias transformadoras, fui impelida a socializar os saberes conquistados nas experiências e no aprofundamento conceitual atravessado de forma autodidata. Em 2014 publiquei o livro "Vivências em biblioterapia: práticas do cuidado através da literatura", que passou a ser editado pela Editora Cândido, a partir de 2018. Em 2015, passei a oferecer cursos livres de Biblioterapia, que se espalharam por diferentes estados e alcançaram profissionais de várias áreas. Desejava percorrer os caminhos acadêmicos para contribuir com a solidificação e a expansão no campo. Porém, que disciplina, que linha de pesquisa, que orientador teriam ressonância com a proposta? Submeti projeto para a seleção de Mestrado em Educação do Programa de Pós-graduação em Educação da Universidade Federal Fluminense (UFF). Tendo sido aprovada, integrei o FIAR (Círculo de estudo e pesquisa Formação de Professores, Infância e Arte), que discutia as interrelações da arte e da educação, o espaço para o sensível na formação de professores, o que representou possibilidade de diálogo e troca de saberes.

Alinhada à proposta do FIAR, realizei a pesquisa/dissertação que teve por objetivo analisar as contribuições do oferecimento de espaços poéticos, simbólicos e expressivos na formação de professores da Educação Infantil. Como parte da investigação, foi desenvolvido o trabalho de campo chamado "Estúdio do sensível" (SEIXAS, 2018a), que consistiu na criação/disposição de um espaço-tempo para experiências com as linguagens e materialidades expressivas, ativando o corpo dançante, literário, artístico-visual, meditativo, criativo. Foram 10 encontros com duas horas de duração cada, para oferecimento de quatro dispositivos culturais: Biblioterapia, Arteterapia, Dança circular e Escrita criativa. O projeto contou com a participação de professoras de instituições de Educação Infantil públicas 


\section{RevistAleph}

localizadas no estado do Rio de Janeiro. Em cada encontro, o acolhimento era feito através da dança circular, seguida de estímulo da literatura, com desdobramento expressivo através das materialidades da arteterapia e finalização com escrita criativa para capturar ressonâncias em escritas num "caderno de bordo". Após as escritas e produções, era o momento partilha oral dos processos e sentidos. Abraçando os preceitos da Biblioterapia, havia o chamado tempo de nutrição literária, com disponibilização de livros infantojuvenis e de poesia. A depender do contexto, a ordem das proposições poderia ser invertida: primeiro convidar à uma atividade expressiva e, durante ou após, oferecer a nutrição literária.

Considerando os objetivos do presente artigo, trarei dados e tecerei relações e discussões referentes às práticas e experiências desencadeadas pelas vivências da Biblioterapia, no trabalho de campo proposto. Nesse contexto, a narrativa a seguir conta de uma das sessões do Estúdio do sensível, quando uma das professoras abraçou o livro "Selvagem" (HUGHES, 2015), outra escolheu “Ana, Guto e o Gato Dançarino" (KING, 2004), uma terceira optou por "O coração e garrafa" (JEFFERS, 2012) e outra, “A força da palmeira” (LOPES, 2014).

No livro "Selvagem", uma menina criada na selva por animais é encontrada e capturada por humanos. Eles tentam moldá-la aos novos padrões de educação, que geram sofrimento pois são incompatíveis com sua natureza. Em "Ana, Guto e o Gato dançarino", dois menestréis chegam numa cidade e percebem que Ana tem mais talentos do que mostra no seu ofício de fazer botas marrons. Decidem ficar para ajudá-la, através da dança, a soltar suas potencialidades. Ela acaba por se transformar em artista respeitada na cidade. "Força da palmeira" conta de uma jovem árvore que, oprimida por uma pedra, começa a crescer para baixo e a expandir suas raízes, o que contribui para um farto crescimento posterior. Em "O coração e a garrafa", uma menina, diante da ausência, decide colocar o coração na garrafa para não sofrer. Com o tempo, percebe que, sem o seu coração, tudo ficou diferente e inviável. Decide então tirá-lo da garrafa, o que descobre que não é fácil. Quem sabe o caminho e a auxilia na solução é uma criança. Foi então percebido um fio tênue que ligava as histórias selecionadas: a contenção da expressão da própria natureza. Dentre as personagens, Ana não produzia suas artes, uma mulher estava com o coração engarrafado, a palmeira crescia para baixo e a selvagem sofria com o processo de domesticação. A escassez de espaços para a autenticidade, a leveza e o fluxo criativo foi evidenciada. A professora que escolheu o livro "O 


\section{RevistAleph}

coração e a garrafa" reconheceu que a contenção, para proteger o coração, faz com que não se tenha acesso à criança interna, que é autêntica, alimentada por campos ampliados de percepção.

Em outra sessão, a intenção era fazer provocações poéticas: coloquei uma cebola e uma laranja no centro da mesa e pedi que as participantes descrevessem, com a máxima riqueza de detalhes, o que estavam vendo. Após esgotar pontos de vista, compartilhei trechos da literatura: "Ode à cebola", de Pablo Neruda e "Laranja de sobremesa", de Astrid Cabral (2014, p. 37), com surpreendentes descrições. O objetivo era incentivar os portais inaugurados através do olhar poético. É como escreve Sophia de Mello Breyner Andresen (2018, p. 895): "A poesia pede-me a inteireza do meu ser; pede-me que viva atenta como uma antena. [...] Pois a poesia é minha explicação com o universo, o meu encontro com as vozes e as imagens." Partimos então para um passeio pelo Campus da Universidade num convite a olhar para os detalhes do caminho com vagar, como se os víssemos pela primeira vez, com olhos de poeta e de criança que inaugura o mundo. A proposta era também capturar iluminuras fotográficas. Durante o trajeto, as docentes relatavam que a sensação era a de que estavam em outro lugar, pela oportunidade de prestar atenção na diversidade de flores, plantas, paisagens, detalhes no caminho, que atropelavam pela pressa e desatenção. A atividade proporcionou resgate de memórias da infância, como a partir do enquadramento fotográfico de numa planta cheia de coquinhos amarelos. Outra professora perguntou: "Como se fotografa o vento?" e me lembrei do verso do poeta Manoel de Barros: "Queria transformar o vento./Dar ao vento uma forma concreta e apta a foto." (BARROS, 2010, p. 384). Ao final do passeio em devaneio, sentamos no gramado, próximo ao mar. Foi dado um tempo para o silêncio, para os sentidos, para o vazio e para a escrita. As produções foram partilhadas e surpreendi-me ao constatar que todas foram feitas em forma poética.

Em outras sessões, também foram ofertados para livre manuseio livros variados de poesia, trechos de literatura brasileira, livros de imagens e até uma tese de doutorado apresentada em forma de quadrinhos, no livro chamado "Desaplanar" (SOUSANIS, 2017), como exemplos de estímulos e ampliação de repertório cultural.

O título da dissertação sintetiza as experiências atravessadas: "Vagar sem pressa no esconderijo da vida alada: em busca de alma na educação" (SEIXAS, 2018a). O espaço criado na formação docente, por meio de linguagens sensíveis, possibilitou respiro, nutrição de 


\section{RevistAleph}

repertório, acesso às vozes interiores provocadas por narrativas escritas e imagéticas da literatura, fomentou atitude reflexiva nas relações consigo mesmas e com os alunos, proporcionou atribuição de sentidos. A experiência permitiu cuidar de quem cuida, ativar universos acessíveis apenas quando ousamos parar e prestar atenção:

[...] os pequenos detalhes não foram feitos para serem notados. Eles foram feitos para serem descobertos. E quando paramos para procurá-los, os pequenos detalhes aparecem. Minúsculos, mas tão presentes, que se tornam imensos. Não existe tesouro maior do que os pequenos detalhes. Um único desses detalhes é suficiente para enriquecer o instante que passa. Um único desses detalhes é suficiente para mudar o mundo (ZULLO, 2013, n.p.).

\section{Considerações finais por histórias a mais}

Se a educação foi submetida aos controles da razão por tanto tempo, é o momento de criar espaço para o respiro, a leveza, a imaginação, a fantasia, a sensibilidade. Sei que muitos educadores, a despeito das más condições de trabalho, dos limites da formação e do desprestígio político-social evidente que sofrem na atualidade, estão comprometidos com uma educação de qualidade, estão fazendo o seu melhor, estudam, buscam ampliar horizontes pessoais e profissionais (fato percebido, inclusive, pela procura crescente dos círculos de biblioterapia que venho conduzindo).

É essencial a criação de um espaço-tempo para contato para escuta e nutrição de dimensões sensíveis, numa perspectiva mais ampla provedora de sentido à multiplicidade de experiências, fora e dentro da escola. É preciso criar refúgios e continentes para o cultivo da alma, acesso às histórias, modelos a se inspirar, numa consciência ativa, sonhadora e imaginante. A biblioterapia, entendida como veículo do sopro na pele da palavra, a cuidar e restaurar histórias e esperança, com metodologia pautada na escuta, no acolhimento e na seleção cuidadosa do material a ser oferecido, apresenta-se como recurso para arar campos humanizantes e culturais, tanto para alunos (independentemente da idade), quanto para professores, exaustos e adoecidos diante de infinitas batalhas dentro e fora da escola.

É preciso ajudar.

Porém primeiro,

Para poder fazer o necessário,

É preciso ajudar-me agora mesmo, 


\section{RevistAleph}

A ser capaz de amor, de ser um homem.

Eu que também me sei ferido e só,

Mas aconchego este animal sonoro

Que reina poderoso no meu peito

(MELLO, 2006, p. 151-152).

\section{Referências}

ALVES, R. Lições de feitiçaria. São Paulo: Edições Loyola, 2003.

ALVES, R. Os três reis. São Paulo: Edições Loyola, 2004.

AMARAL, M. A garrafa e a rolha. Rio de Janeiro: Lacre, 2015.

ANDRESEN, S. Obra poética. Rio de Janeiro: Tinta-da-china Brasil, 2018.

BETHÂNIA, M. Caderno de poesias. Belo Horizonte: Editora UFMG, 2015.

ASTRID, C. Alameda. Rio de Janeiro: Ibris Libris, 2014.

BACHELARD, G. $\mathbf{O}$ ar e os sonhos: ensaio sobre a imaginação do movimento. São Paulo: Martins Fontes, 2001.

BARROS, M. Poesia completa. São Paulo: LeYa, 2010.

BARROS, M. Biblioteca Manoel de Barros/Matéria de poesia. São Paulo: LeYa, 2013.

BORGES, I. Bíblica Chorona. Rio de Janeiro: Lago de Histórias, 2018.

CABRAL, A. Rasos d'água. Manaus: Valer, 2004.

CALDDIN, C. Biblioterapia: um cuidado com o ser. São Paulo: Porto de Ideias, 2010.

CHEVALIER, J. GHEERBRANT, A. Dicionário de símbolos: (mitos, sonhos, costumes, gestos, formas, figuras, cores, números). Rio de Janeiro: José Olympio, 2012.

COUTO, M. O fio das missangas. São Paulo: Companhia das Letras, 2009.

FRANCO, B. Ernesto. São Paulo: Companhia das Letrinhas, 2016.

FREIRE, P. Pedagogia da autonomia: saberes necessários à prática educativa. São Paulo: Paz e Terra, 1996.

FREIRE, P. Professora sim tia não - cartas a quem ousa ensinar. São Paulo: Olho d'Água, 1995.

FURNARI, Eva. Nós. São Paulo: Global, 2003.

GALEANO, E. O livro dos abraços. Porto Alegre: L\&PM, 2000. 


\section{RevistAleph}

GALLIAN, D. A literatura como remédio: os clássicos e a saúde da alma. São Paulo Martin Claret, 2017.

HILLMAN, J. O código do ser: uma busca do caráter e da vocação pessoal. Rio de Janeiro: Objetiva, 1997.

JECUPÉ, K. Tupã Tenondé: A criação do Universo, da Terra e do Homem segundo a tradição oral Guarani. São Paulo: Peirópolis, 2001.

JUNG, C. G. Memórias, sonhos, reflexões. Rio de Janeiro: Nova Fronteira, 1975.

JUNG, C. G. Psicologia e Alquimia. 6 ed. - Petrópolis, RJ : Vozes, 2012.

KILOMBA, G. Memórias da plantação. Rio de Janeiro: Cobogó, 2019.

LÓPES, Anabella. A força da palmeira. Rio de Janeiro: Pallas Mini, 2014.

MELLO, L. Nise da Silveira: caminhos de uma psiquiatra rebelde. Rio de Janeiro: Automática Hólos Consultores Associados, 2015.

MELLO, T. Poemas preferidos pelo autor e seus leitores: edição comemorativa dos 75 anos do autor. Rio de Janeiro: Bertrand Brasil, 2006.

OUAKNIN, M. Biblioterapia. São Paulo: Edições Loyola, 1996.

QUEIRÓS, B. Antes do depois. São Paulo: Global, 2018.

PENNAC, D. Como um romance. Rio de Janeiro: Rocco, 1993.

PETIT, M. A arte de ler ou como resistir à adversidade. São Paulo: Editora 34, 2009.

PETIT, M. Os jovens e a leitura: uma nova perspectiva. São Paulo: Editora 34, 2009.

QUEIRÓS, B. Para ler em silêncio. São Paulo: Moderna, 2007.

QUEIRÓS, B. Vermelho amargo. São Paulo: Cosac Naify, 2011.

QUINTANA, M. Antologia poética. Porto Alegre: L\&PM, 1999.

RANCIÉRE, J. Partilha do sensível: estética e política. São Paulo: Editora 34, 2009.

ROSA, S. O menino Nito. Rio de Janeiro: Pallas, 2008.

SEIXAS, C. Vagar sem pressa no esconderijo da vida alada. Dissertação (Mestrado em Educação). Niterói, RJ. Faculdade de Educação - UFF, 2018a.

SEIXAS, C. Vivências em biblioterapia: práticas do cuidado através da literatura. Niterói: Cândido, 2018b. 


\section{RevistAleph}

SOUSA, C. Biblioterapia no Brasil e na Polônia: distâncias e aproximação a partir da literatura científica. Dissertação (mestrado) - Universidade Federal de Santa Catarina, Centro de Ciências da Educação, Programa de Pós-Graduação em Ciência da Informação, Florianópolis, 2017.

SOUSANIS, N. Desaplanar. São Paulo: Veneta: 2017.

TODOROV, T. A literatura em perigo. Rio de Janeiro: DIFEL, 2016.

VAZ, Sérgio. Colecionador de pedras. São Paulo: Global, 2013.

ZULLO, G. Os pássaros. São Paulo: Editora 34.

Data do envio: $14 / 04 / 2020$

Data do aceite: $17 / 06 / 2020$. 